\title{
The loan to value ratio for housing in Spain over the period 2004-2016
}

Olympia Bover, María Torrado and Ernesto Villanueva 


\begin{abstract}
The ratio between the amount of mortgage loans and the value of housing (the loan to value ratio) is a useful indicator for studying the financial situation of households. Two main price indicators are used to measure loan to value ratios for housing in Spain at the time of purchase: the transaction price recorded at the Property Registry and the appraisal value. Having generated a sample in which both price indicators refer to the same set of housing, the median loan to value ratio between 2004 and 2007 is found to stand between $70 \%$, when the appraisal value is used, and $107 \%$, when the transaction price is used. The difference between these two ratios narrowed from 2010, with the loan to value ratio using the appraisal value remaining at around $70 \%$, while the ratio based on the transaction value fell to $80 \%$. The Spanish Survey of Household Finances (EFF), conducted by the Banco de España, is an alternative data source, allowing a loan to value ratio to be obtained directly from households' responses. This ratio, based on EFF data, has evolved in a similar way to the one derived from the transaction prices recorded at the Property Registry.
\end{abstract}

Keywords: mortgages, house prices, loan to value ratio.

JEL codes: D14, G21, E21. 
The authors of this article are Olympia Bover, María Torrado and Ernesto Villanueva of the Directorate General Economics, Statistics and Research.

Introduction

The ratio of the mortgage granted to the price paid for housing (the "loan to value ratio") is often used as an indicator of the strength or vulnerability of the financial situation of households. A high ratio indicates that households are making small down payments at the time of purchasing housing and therefore will have to make relatively high payments over the life of the loan.

Two house price indicators are generally used in Spain to calculate this ratio: (i) the appraisal value, entered in the Mortgage Record of the Association of Registrars (Colegio de Registradores), which goes back to 2004; and (ii) the house prices stated in the deeds and entered in the Property Transfer Record. The first indicator is constructed using a database containing information on the value of all new mortgages and on the appraisal value of the property for auction. The second indicator is derived from the database containing the transaction prices declared to the Property Registry (Registro de la Propiedad). As can be seen by comparing the first two rows of Table 1, the difference between them (and, therefore, between the corresponding loan to value ratios) was substantial between 2004 and 2008, when median appraisal values exceeded transaction prices by $30 \%$. The difference narrowed, however, between 2009 and 2016.

Appraisal values are only available for houses with mortgages, not for all houses sold. In fact, many appraised houses are not sold, since a mortgage may be granted to finance consumption or investment, while there are also houses that are transferred without a mortgage being granted to finance the purchase. Thus, transaction prices and appraisal prices do not necessarily refer to the same set of properties, which makes it difficult to compare them.

In this article we construct a database from the Mortgage Record and the Property Transfer Record, using variables common to both, which reduces the differences arising from the fact that the composition of the original datasets is not the same. This new database (the "linked sample") contains the transaction price and the appraisal value for, essentially, the same houses. The transaction prices and the appraisal prices in the linked sample are similar to those shown in Table 1, so this sample is used in the rest of the analysis.

The discrepancy between house values naturally generates differences in the loan to value ratio. Thus, secondly, we analyse the distribution of the values of the loan to value ratio using both the appraisal value and the transaction price. Analysing the changes over time in the distribution of these ratios also makes it possible to characterise the adjustment made over the cycle.

Finally, an alternative source of information on the value of housing is used, namely the Spanish Survey of Household Finances (EFF by its Spanish initials), which is conducted by the Banco de España. The EFF has, since 2002, been asking a representative sample of Spanish households the value of their house at the time of purchase and the initial amount of any mortgage on such house. The information obtained by the survey between 2002 


\begin{tabular}{lrrrrrrrrrrrrrr} 
& 2004 & 2005 & 2006 & 2007 & 2008 & 2009 & 2010 & 2011 & 2012 & 2013 & 2014 & 2015 & 2016 \\
\hline
\end{tabular}

SOURCE: Banco de España.

\section{Previous studies}

and 2014 provides loan to value ratios similar in magnitude to those obtained using the transaction price as the value of housing.

The article is organised as follows. After this introduction, the second section summarises previous studies in this area. The third section discusses the various databases of the Association of Registrars, the items they include and the link between the samples considered. The fourth section discusses the results obtained using the linked sample. Finally, the fifth section offers results using the EFF.

A number of studies have shown that the information in Spain on the selling prices of houses varies according to the data source used. One of the most frequently used prices is derived from the appraisal value of a property when it is mortgaged. A second measure is obtained from the Property Transfer Record. However, neither of these sources necessarily reflect the actual prices at which properties are sold. Appraisal values are estimates of a property's market value made by professionals for various purposes, such as to calculate the capital requirements of financial institutions, while the transaction price recorded by the Association of Registrars is a value declared by the purchaser and the vendor which is used as the tax base for VAT and Transfer Tax (Impuesto de Transmisiones Patrimoniales). Given these discrepancies, it is not surprising that the loan to value ratio varies according to the measure used.

García-Montalvo and Raya (2012) construct a sample of transactions brokered by a real estate company with a nationwide presence between 2004 and 2011. The advantage of this database is that it contains the prices actually agreed in the transactions. Linking this sample to the information of the Association of Registrars enables three measures of prices to be compared: the value agreed in the transaction (the selling price); the transaction price declared at the Property Registry; and the appraisal value of the property in the period.

García-Montalvo and Raya (2012) find that the three measures differ for the transactions analysed. First, the transaction price declared to the Property Registry is slightly lower than the selling price. ${ }^{1}$ Second, the selling price is significantly lower than the appraisal value. Given these differences in the value of the acquired property, the average loan to

1 Part of these limited differences may arise because some values recorded in the Property Transfer Record correspond not to the actual value of the transaction but to the minimum values for deeds set by various regional governments. 
value ratio when the appraisal value is used in their sample is $83 \%$, while it is $110 \%$ when the transaction value is used. ${ }^{2}$

Akin et al. (2014) extend the analysis of the previous article by comparing loan to value ratios during the expansion and during the recession, and show that they decreased from 2007.

These two studies use highly comprehensive information on transactions, albeit limited to those brokered by a specific real estate company. As these authors mention, on account of the characteristics of the real estate company considered, the sample is overrepresentative of large cities, although the housing considered is of similar price and size to that in the total database of the Association of Registrars.

Masier and Villanueva (2011), meanwhile, use data from the Survey of Household Finances (EFF), between 2002 and 2005, to analyse the behaviour of credit conditions during the expansion that preceded the financial crisis of 2008. Specifically, the study uses retrospective information on the amount of mortgages and the value of houses for households acquiring a main residence between 1992 and 2005. This study shows that the median loan to value ratio at the time of acquisition stood at around $75 \%$ in the period before 1998, while it reached $95 \%$ for the transactions completed in the period 2003-05.

In the aforementioned studies, the ratios between the loan and the acquisition value of the housing exceed those obtained using the appraisal value. This article therefore seeks to make two contributions. First, as described below, the differences are calculated between the appraisal values and transaction prices, for all the mortgages linked to property sales in Spain between 2004 and 2016. Second, it analyses, on the one hand, how the dispersion of appraisal values around transaction prices has varied over the business cycle and, on the other, how the loan to value ratio depends on the house price measure used.

Databases of Association of Registrars
The Mortgage Record of the Association of Registrars contains information on the value of all mortgages on properties, as well as the appraisal value for auction of such properties. ${ }^{3}$ It also contains information both on the registry and the municipality in which the registration was made and on the date of execution of the deed. ${ }^{4}$ Lastly, the record includes information such as the nature of the property, whether the house is market price or administered price, the stage of construction and various measures of floor area (including useful and built floor area, the latter being the most commonly used). For the purposes of this exercise, the mortgages selected are home loans granted to individuals, either in the year of registration or in the previous year. Only euro-denominated transactions are included.

For its part, the Property Transfer Record covers transfers of properties. For the purposes of this exercise, criteria similar to those used in the previous case are applied: only transfers

2 There is evidence in the United States on differences between appraisal and transaction values. Specifically, Cho and Megbolugbe (1996) find that on average the appraisal value of a house exceeds the transaction value, net of transaction costs. However the size of the difference is small: only in $5.5 \%$ of cases was there a positive difference of more than $10 \%$. See Nakamura (2010) for a discussion.

3 The appraisal value for auction, which is recorded in the Mortgage Record, may be less than the appraisal value in certain loans (for example, those that are not securitised). Various pieces of legislation since 2009 have limited this possibility. In any case, this article shows (in particular in Charts 2 and 3) that the proportion of abnormally low appraisal values is small. At the same time, some of the housing affordability indicators published by the Banco de España also use the Mortgage Record to analyse the loan to appraisal value ratio.

4 The registry and the municipality are different geographical units, with some overlap. In municipalities such as Madrid and Barcelona there are several registries. By contrast, a single registry may cover the transactions of several small municipalities. In this study the smallest geographical unit is used throughout. 
by individuals of full title to houses, by means of sale (excluding swaps and other transactions) are considered.

As mentioned above, these two records do not necessarily include the same transactions.

APPRAISAL VALUE AND TRANSACTION PRICE

LINKED SAMPLE
Even when the sale and the mortgage relate to the same property, the appraisal value may differ from the transaction price. For example, the market price of a property may be affected by expected changes in the classification of the land for building purposes or by possible infrastructure developments in the area. However, Ministerial Order ECO $805 / 2003$ requires that the appraisal value of a real estate asset should not reflect the influence of future events that are not certain to occur. ${ }^{5}$ The most common way of obtaining the appraisal value is by comparison: the average price per square metre of six properties similar to the one being valued ${ }^{6}$ is calculated, and this is multiplied by the floor area of the property in square metres. This value is used when calculating financial institutions' capital requirements.

The transaction value, by contrast, is reported by the purchaser and vendor in the document which publicly records the sale. This value serves as the tax base for VAT (in the case of new housing) or Transfer Tax (in the case of second-hand housing).

Owing to the way in which the two databases are constructed, a house purchase financed by a mortgage is entered in both the Property Transfer Record and the Mortgage Record. Thus, these two records can be linked using the common variables. This study uses as linking variables the registry at which the property transaction was recorded or the mortgage created, the date of execution of the deed, the year of entry in the record, the nature of the property (apartment, apartment with appurtenances, terraced housing or detached housing), the type of property (free market or government sponsored), the status of the property (new build or second hand) and the floor area. $^{7}$

The size of the resultant linked sample ranges between 78,637 transactions in 2013 and 361,026 in 2006 . The sample includes approximately $40 \%$ of all house sales made each year and excludes non-mortgage house purchases (or those for which the mortgage has not been identified).

The degree of reliability of the subset of linked transactions is adequate, owing to the high degree of similarity between the observations in the two databases. For example, in 2008, in $96 \%$ of cases there is just one transaction that has exactly the same characteristics as the housing unit for which the mortgage was arranged. In $2.7 \%$ of cases there are two transactions associated with a mortgage, and three or more transactions in the remaining $0.7 \%$. In addition, since 2012 , the databases include the property cadastral reference, which is an indicator that is unique to each separate property in Spain. In consequence, it is possible to compare how many of the link-ups made in our study share the same cadastral reference. The percentage is $100 \%$ in the subsample of transactions with a 20-digit cadastral reference.

5 See the Preamble and Article 4 of Ministerial Order ECO No 805 of 2003 (Official State Gazette of 9 April 2003).

6 Other possible methods are income capitalisation (based on a calculation of the present value of the future rental income the property may generate) and the cost method (based on the cost of replacing the property being valued.

7 Both records include two measures of floor area: useful floor area and built floor area. In the link between the two databases, all the declared floor areas (in $\mathrm{cm} 2$ ) must coincide. 
The chart depicts the changes in the period 2004 to 2016 in the median appraisal value per $\mathrm{m}^{2}$ and the median transaction price per $\mathrm{m}^{2}$ (left-hand scale) and the ratio between the two in the linked sample (right-hand scale). The median transaction price is the middle point, with half of all sales made below that price and half above that price. The median price is used because it is less sensitive to outliers than the average price. Between 2004 and 2008 the median transaction price amounted to some $65 \%$ of the median appraisal value. From 2008 , the appraisal value per m2 fell by more than the transaction price, and from 2015 the ratio between the two indicators stabilised around $90 \%$.

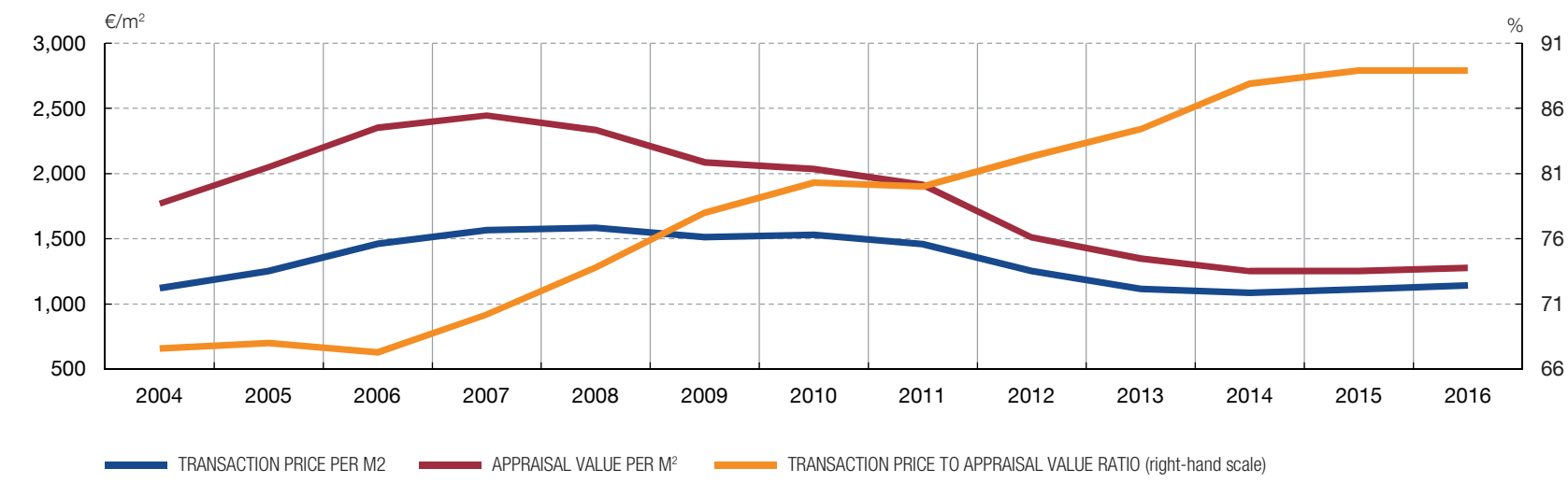

SOURCES: Linked sample of Mortgage and Property Transfer Records, 2004 to 2016.

Download

Linked sample results

DISPERSION OF RATIO BETWEEN APPRAISAL VALUES AND TRANSACTION PRICES
Between 2004 and 2008, the transaction price per square metre was generally around $66 \%$ of the appraisal price declared to the Notary Public, although from 2009 this percentage rose, reaching $90 \%$ in 2016 (see the third row of Table 1). When the transaction price and the appraisal value are compared in the linked sample, the ratio between the two is virtually the same as in the total sample (see the fourth row of Table 1). Accordingly, the fact that the transactions recorded in the Mortgage Record differ from those included in the Property Transfer Record does not explain the differences between transaction prices and appraisal values.

The ratio between transaction prices and appraisal values changed over the last economic cycle. Between 2007 and 2014, the appraisal value in the linked sample fell by more than the transaction price, whereas from 2015 the ratio between these two indicators stabilised at around $90 \%$ (see Chart 1).

As indicated, the appraisal value of a housing unit may differ from its transaction price, since the latter reflects uncertain elements, such as the possibility of future land reclassification or infrastructure development in the area. ${ }^{8}$ However, as the most common valuation method is to use the selling price of properties with similar characteristics, there should be a link between the two variables. Chart 1 shows that between 2004 and 2016 the gap between the median appraisal value and the median transaction price recorded in the Property Registry narrowed.

However, in addition to the narrowing of this gap between the median magnitudes, there was also a change in the dispersion of property transaction prices around appraisal values. Chart 2 depicts these changes, showing the relative frequency of different values of the ratio between the transaction price and the appraisal value at three points of the last

8 See the Preamble and Article 4 of the above-mentioned Ministerial Order 805 of 2003 (Official State Gazette of 9 April 2003). 
The vertical axis shows the proportion of house sales for each value of the transaction price to appraisal value ratio for different years. The ratio is less than one when transaction prices are lower than appraisal values. Between 2006 and 2016 the proportion of house sales in which the transaction price was much lower than the appraisal value fell, while the proportion of transactions in which the transaction price was equal to or higher than the appraisal value grew.

\section{TRANSACTION PRICE TO APPRAISAL VALUE RATIO, 2006}

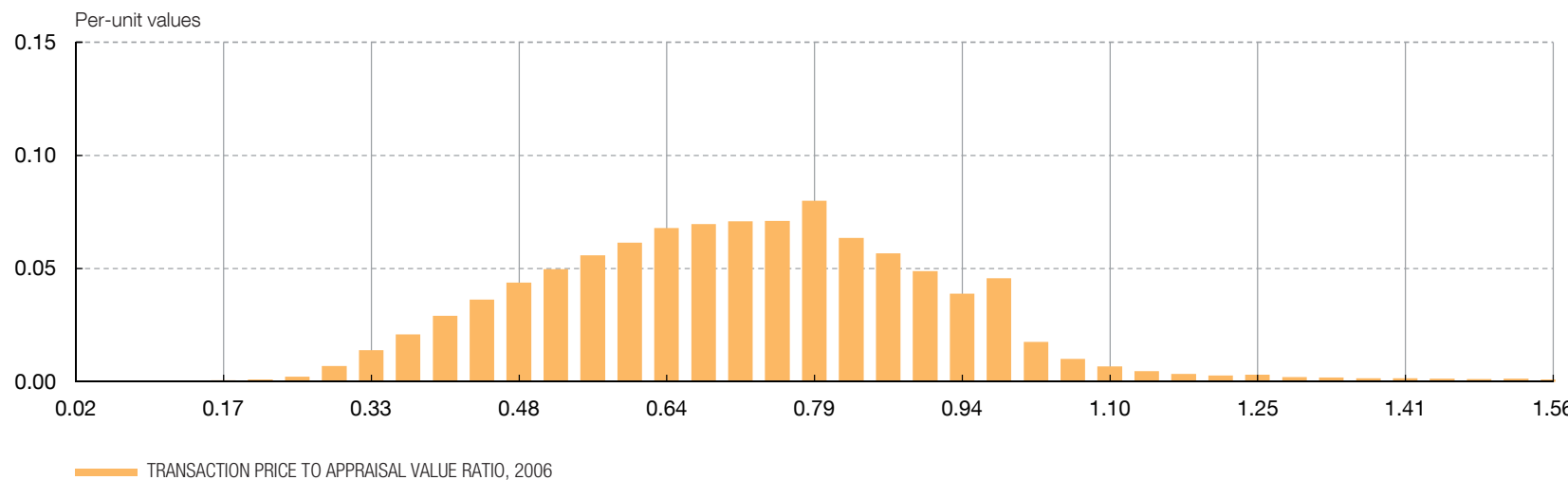

2 TRANSACTION PRICE TO APPRAISAL VALUE RATIO, 2010

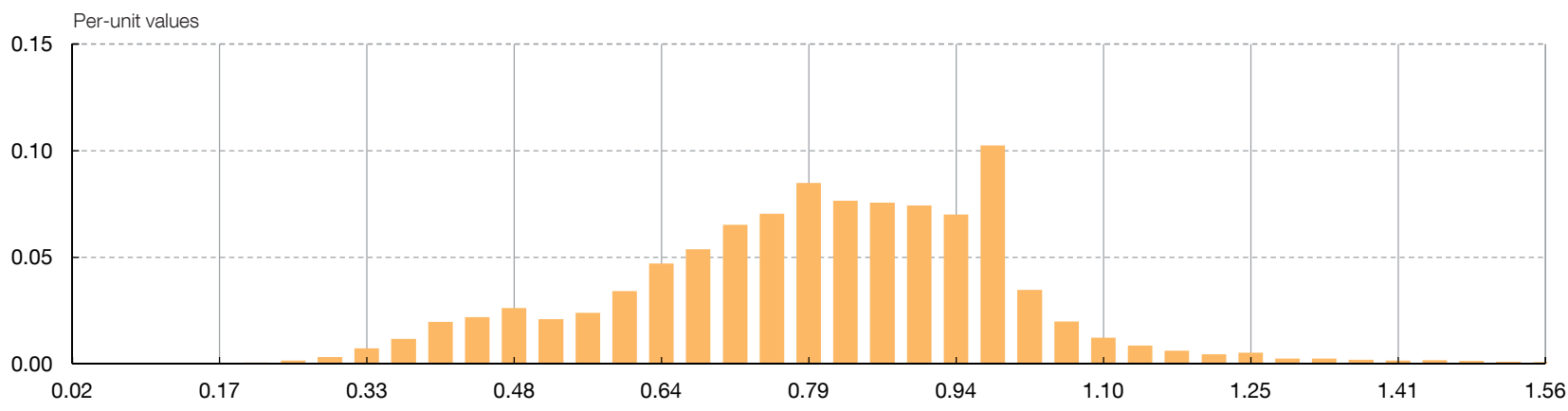

- TRANSACTION PRICE TO APPRAISAL VALUE RATIO, 2010

3 TRANSACTION PRICE TO APPRAISAL VALUE RATIO, 2016

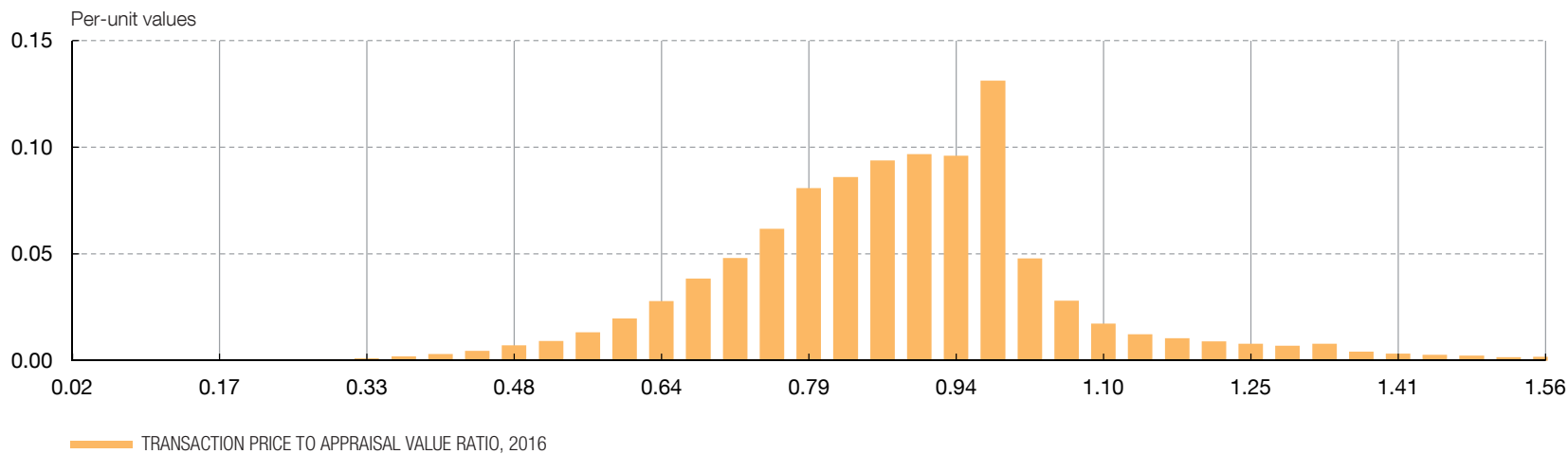

SOURCES: Linked sample of Mortgage and Property Transfer Records, 2004 to 2016.

Download 
DIFFERENCES IN LOAN TO VALUE RATIOS

DISTRIBUTION OF LOAN TO VALUE RATIOS economic cycle: 2006 (expansion), 2010 (recession) and 2016 (recovery). When the ratio has a value of less than one, the appraisal value is higher than the transaction price, and vice versa when it has a value of more than one.

In 2006 there was a high degree of dispersion of appraisal values around transaction prices. ${ }^{9}$ In a quarter of the house sales in the linked sample the transaction price was less than half the appraisal value (in other words, $25 \%$ of the observations in Chart 2.1 have a value below 0.5 ). Only in one of every ten transactions was the transaction price equal to or higher than the appraisal value (ratio equal to or higher than one in Chart 2.1).

In 2010 not only was it observed that the gap between appraisal values and transaction prices had narrowed, but also that appraisal values were more highly concentrated around transaction prices. For instance, in one of every seven house sales, the transaction price was less than half the appraisal value (in 2006 this was the case in one of every four house sales). Moreover, in one of every ten house sales, the transaction price coincided with the appraisal value (ratio equal to one in Chart 2.2). By contrast, in 2006 this was the case in only one of every 25 house sales.

Lastly, in 2016 there were hardly any house sales in which the transaction price was less than half the appraisal value. In one of every four house sales in the linked sample the appraisal value was equal to or less than the transaction price, a percentage that is $15 \mathrm{pp}$ higher than that observed in 2006.

To sum up, over the economic cycle, appraisal values fell proportionately more than transaction prices. This coincided with an increase in the number of house sales in which the appraisal value was equal to or less than the transaction price. Even so, in 2016 there was a high proportion of house sales in the linked sample in which the appraisal value was higher than the transaction price.

Naturally, the differences in housing values indicated above are reflected in discrepancies in the calculation of the loan to value ratio according to which price or value is used (see Tables 2 and 3). Taking the linked sample, the median ratio of mortgage loan to recorded sale value in 2006 was $107 \%$, significantly higher than the median ratio of loan to appraisal value in the same year which was 70\% (see Table 3). Between 2007 and 2016 the loan to transaction price ratio in the linked sample gradually declined, from $105 \%$ in 2007 to $80 \%$ in 2012 and following years. By contrast, the loan to appraisal value ratio was steady at around $70 \%$ throughout the period 2004 to 2016 .

The distribution of the ratios according to whether they are loan to appraisal value or loan to transaction price is illustrative. Chart 3 depicts the relative frequency of different values of the loan to appraisal value and loan to transaction price ratios at different points of the cycle: 2006 (expansion), 2010 (recession) and 2016 (recovery).

In 2006, the loan to appraisal value ratio was highly concentrated around two values: $80 \%$ and $100 \% .{ }^{10}$ Specifically, in $11 \%$ of mortgages in the linked sample the ratio was $80 \%$,

9 Dispersion between transaction prices and appraisal values is a relative magnitude. This article refers to the dispersion of appraisal values around transaction prices because the first variable has a higher standard deviation than the second one.

10 In this study a mortgage is considered to be granted for $80 \%$ of the transaction price or appraisal value when the corresponding loan to value ratio is between $78.75 \%$ and $81.25 \%$. Similarly, it is considered to be granted for $100 \%$ when the ratio is between $98.75 \%$ and $101.25 \%$. 


\begin{tabular}{|c|c|c|c|c|c|c|c|c|c|c|c|c|c|}
\hline & 2004 & 2005 & 2006 & 2007 & 2008 & 2009 & 2010 & 2011 & 2012 & 2013 & 2014 & 2015 & 2016 \\
\hline \multicolumn{14}{|l|}{ Unlinked samples } \\
\hline $\begin{array}{l}\text { Median loan to median } \\
\text { appraisal value ratio }\end{array}$ & 68 & 66 & 66 & 68 & 59 & 52 & 54 & 54 & 49 & 50 & 56 & 60 & 63 \\
\hline $\begin{array}{l}\text { Median loan to median } \\
\text { transaction value ratio }\end{array}$ & 108 & 107 & 107 & 110 & 85 & 71 & 71 & 71 & 64 & 68 & 74 & 78 & 80 \\
\hline
\end{tabular}

SOURCE: Banco de España.

MEDIAN VALUE OF LOAN TO VALUE RATIO

\begin{tabular}{|c|c|c|c|c|c|c|c|c|c|c|c|c|c|}
\hline & 2004 & 2005 & 2006 & 2007 & 2008 & 2009 & 2010 & 2011 & 2012 & 2013 & 2014 & 2015 & 2016 \\
\hline \multicolumn{14}{|l|}{ Linked sample } \\
\hline Loan to appraisal value ratio & 70 & 70 & 70 & 70 & 67 & 67 & 70 & 69 & 66 & 66 & 68 & 71 & 72 \\
\hline Loan to transaction price ratio & 103 & 106 & 107 & 105 & 96 & 89 & 88 & 86 & 80 & 80 & 80 & 80 & 80 \\
\hline \multicolumn{14}{|l|}{ Survey of household finances (EFF) } \\
\hline Loan to purchase value ratio (a) & & 91 & & & 97 & & & $89^{\star}$ & & & $74^{\star}$ & & \\
\hline
\end{tabular}

SOURCE: Banco de España.

a Fewer than 100 observations.

whereas $5 \%$ of the mortgages were granted for $100 \%$ of the appraisal value. The $80 \%$ level coincides with a regulatory threshold; above that level the cost of capital associated with mortgage origination is higher (see, for example, Banco de España Circular 3/2008). In addition, accounting regulations call for different specific or general provisions to be recorded if the loan to appraisal value ratio is over $80 \% .{ }^{11}$ On the other hand, very few mortgages were granted for an initial sum in excess of the appraisal value.

The distribution of the loan to transaction price ratio in 2006 was very different from that described above for the case of appraisal values. First, there was no concentration of the ratio around $80 \%$, but there was concentration around $100 \%$. Almost half the mortgages granted in 2006 exceeded the transaction price declared to the Registrars.

The distribution of the mortgage to appraisal value ratio in 2010 was very similar to that observed in 2006. However, the mortgage to transaction price ratio underwent two major changes. First, the proportion of mortgages the amount of which exceeded the transaction price halved, down from one of every two to one of every four house sales. Second, between 2006 and 2010, the proportion of mortgages that amounted to between $80 \%$ and $100 \%$ of the transaction price increased.

Lastly, the distribution of the loan to appraisal value ratio underwent minor changes between 2010 and 2016. In 2016 a high proportion of mortgages with a loan to appraisal value around $80 \%$ was still observed, but the relatively high number of mortgages concentrated around $100 \%$ was no longer observed $(5 \%$ of the total in the linked sample).

11 See, for instance, page 14 of the notes to Return T.10 on credit risk coverage (Spanish version only) https:// www.bde.es/f/webbde/INF/MenuVertical/Supervision/Normativa_y_criterios/informacion/contabilidad/ informacion_be_6_2008/ficheros/es/ind_t10.pdf. 
The vertical axis shows the proportion of house sales for each value of the loan to value ratio for different years. In 2006 half of the mortgages granted exceeded the transaction price. In 2016 this was the case in one out of ten mortgages. By contrast, there was little change in the loan to appraisal value ratio. Each year, around $15 \%$ of house purchases, the mortgage granted amounted to $80 \%$ of the appraisal value.

\section{DISTRIBUTION OF LOAN TO VALUE RATIOS IN LINKED SAMPLE (2006)}

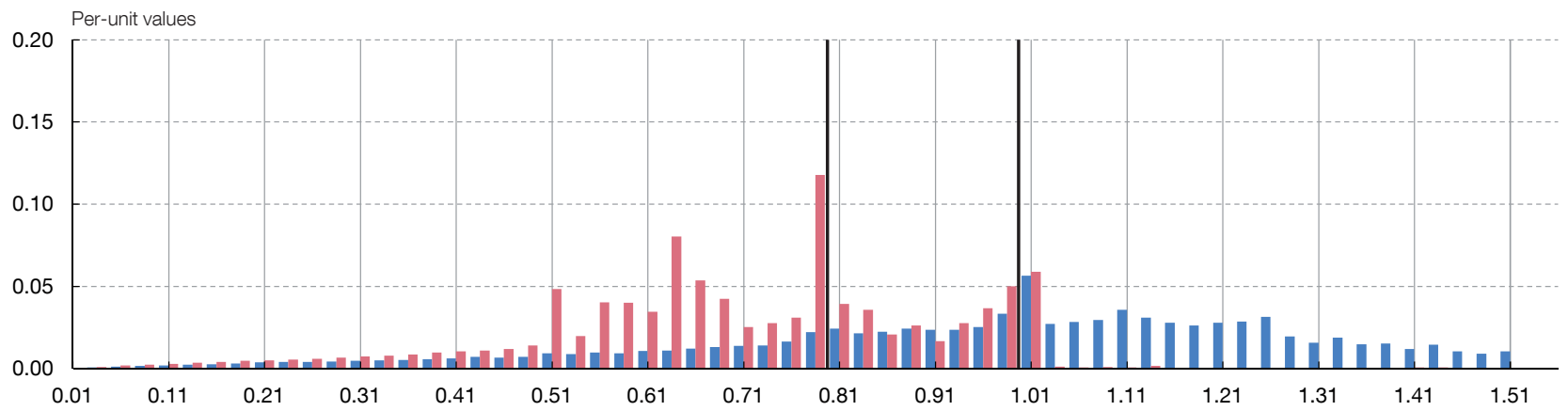

LOAN TO TRANSACTION PRICE RATIO 2006

\section{DISTRIBUTION OF LOAN TO VALUE RATIOS IN LINKED SAMPLE (2010)}

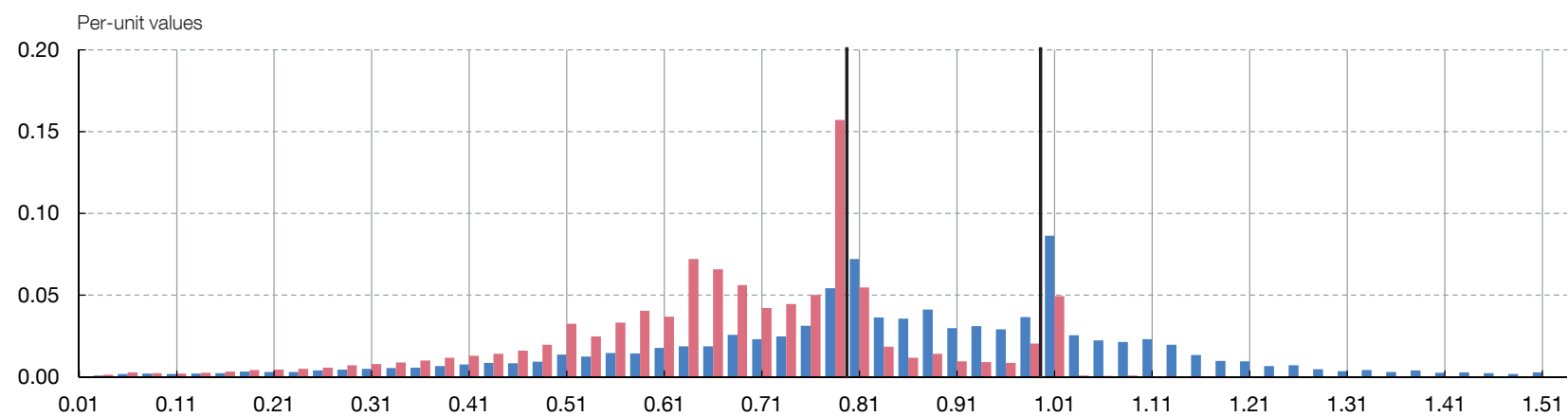

OAN TO TRANSACTION PRICE RATIO 2010

\section{DISTRIBUTION OF LOAN TO VALUE RATIOS IN LINKED SAMPLE (2016)}

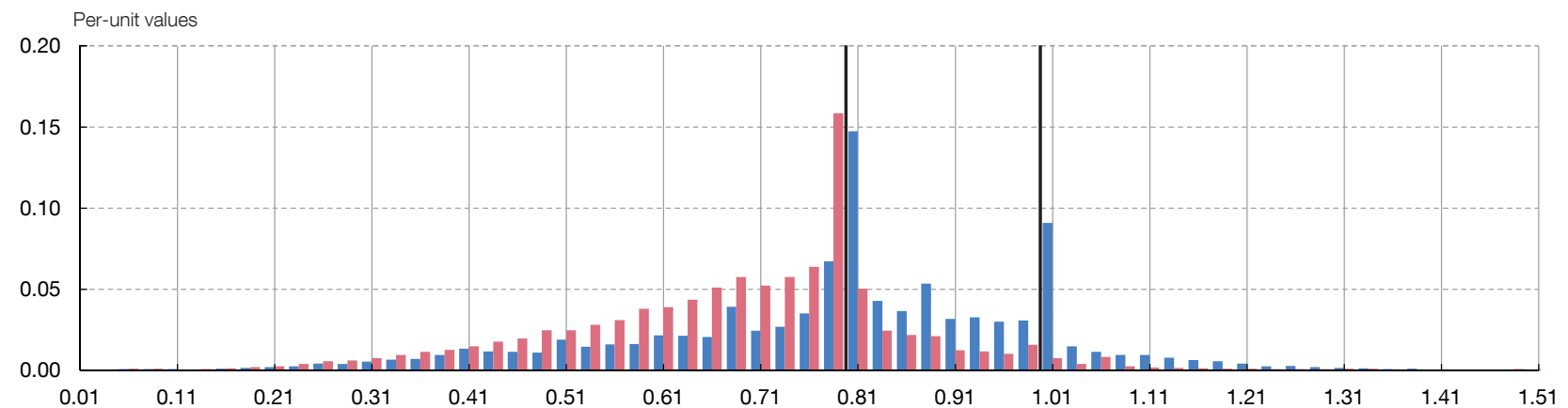

LOAN TO TRANSACTION PRICE RATIO 2016

LOAN TO APPRAISAL VALUE RATIO 2016

$80 \%$ AND $100 \%$ RATIO

SOURCES: Linked sample of Mortgage and Property Transfer Records, 2004 to 2016. 
The median loan to value ratio in the Spanish Survey of Household Finances (EFF) shows a similar level and pattern to that of the loan to transaction price ratio.

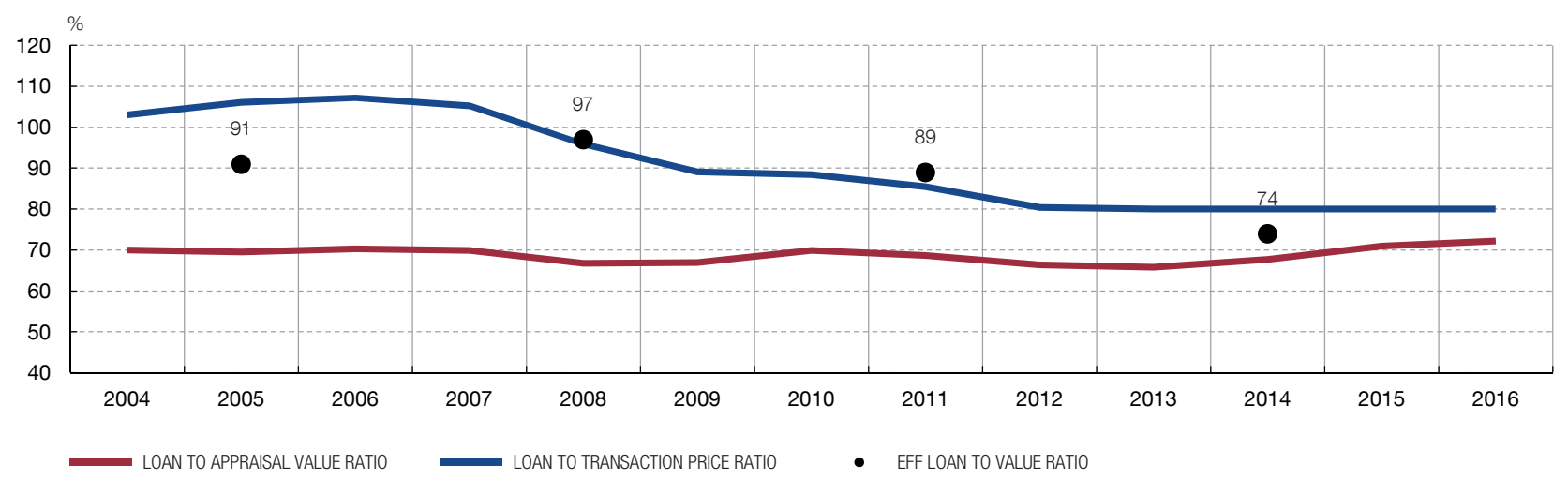

SOURCES: Linked sample of Mortgage and Property Transfer Records, 2004 to 2016, and EFF.

Download

RESULTS SUMMARY

Alternative data sources: Spanish Survey of Household Finances
The distribution of the loan to transaction price ratio remained highly concentrated around $100 \%$ (in 2016 approximately $9 \%$ of mortgages were granted for the full transaction price recorded in the Property Registry). Lastly, the proportion of loans whose principal exceeded the transaction price continued to decline: in $2016,10 \%$ of the mortgages in the linked sample exceeded the transaction price declared in the Property Registry, a figure which is $15 \mathrm{pp}$ lower than that observed in 2010.

Between 2004 and 2008, appraisal values in the linked sample rose at a faster pace than transaction prices, and then fell more sharply than transaction prices between 2008 and 2016. During the expansionary period, only $10 \%$ of transaction prices were higher than appraisal values, while in $25 \%$ of cases the appraisal value was more than double the transaction price. Both percentages gradually eased between 2008 and 2016, as the dispersion of appraisal values around transaction prices decreased. Even so, in 2016 there was still a gap between appraisal values and transaction prices .

As a result of the greater fluctuation in appraisal values observed over the cycle, the loan to appraisal value ratio held relatively steady over time. The median loan to appraisal value ratio remained constant at around $70 \%$ throughout the cycle, and in all the years considered between $10 \%$ and $15 \%$ of house sales had loan to value ratios around the regulatory threshold of $80 \%$.

By contrast, fluctuations in transaction prices were less severe than those observed in appraisal values (see Chart 1). In consequence, the developments in the loan to transaction price ratio in the linked sample were markedly different from those in the loan to appraisal value ratio. The median loan to transaction price ratio fell gradually, from $107 \%$ in 2006 to $80 \%$ in 2016 . This decline was associated with the drop in the proportion of mortgages the amount of which exceeded the total transaction price.

Given the discrepancy between appraisal values and transaction prices recorded in the Property Registry, alternative data sources, such as the Banco de España's Survey of Household Finances (EFF) should be analysed. The households interviewed for the survey provide retrospective information on the value of the house purchased (excluding taxes) 
and the amount of the mortgage arranged to finance the purchase. Accordingly, the five survey waves available may be used to calculate the developments in the ratio between mortgage loans and housing values in the period 2002 to 2014.

The results are shown in the last row of Table 3. The median ratio between the initial loan and the price actually paid for the housing acquired for the period 2006 to 2009 in the 2008 Survey (EFF2008) was 97\%, compared with 91\% for the period 2002 to 2005. From 2009 the median ratio between the mortgage granted and the price paid gradually declined, down to less than $80 \%$ in the period 2012 to 2014 (albeit, in the case of the latest estimate, based on a small sample).

In short, as Chart 4 shows, both the levels and the changes in the loan to value ratio according to the EFF data are similar to the levels and changes in the loan to transaction price ratio throughout the sample period, and both ratios are generally higher than the ratio based on appraisal values, especially during the real estate boom that preceded the crisis.

AKIN, A., J. G. MONTALVO, J. G. VILLAR, J. L. PEYDRÓ and J. M. RAYA (2014), The Real Estate and Credit Bubble: Evidence from Spain, SERIES Volume 5, Issue 2-3: 223-243.

CHO, M. and F. ISAAC MEGBOLUGBE (1996), An Empirical Analysis of Property Appraisal and Mortgage Redlining, Journal of Real Estate Finance and Economics, 13 (July), pp. 45-55.

GARCIA-MONTALVO, J. and J. RAYA (2012), What's the value of Spanish Real Estate?, Spanish Economic and Financial Outlook 4, pp. 22-28.

MASIER, G. and E. VILLANUEVA, (2011) Consumption and Initial Mortgage Conditions: Evidence from Survey Data, Banco de España Working Paper 1101.

NAKAMURA, L. (2010), How much is that home really worth? Appraisal bias and house-price uncertainty, Business Review Q1, pp. 11-22. 